\title{
CARACTERISTICAS TECNOLOGICAS Y USO INDUSTRIAL DE NUEVAS ESPECIES FORESTALES DE LA AMAZONIA PERUANA *
}

Heiter Valderrama Freyre **

\section{RESUMEN}

La extracción selectiva de especies maderables de nuestros bosques, con la mala política de manejo utilizado en los años anteriores, originó prácticamente la desaparición de especies valiosas y requeridas comercialmente en el mercado. Sin embargo, en el ámbito nacional e internacional existe mercado asegurado para productos terminados o semielaborados a base de madera de especies tradicionales o de otras con características similares.

El presente trabajo da a conocer los resultados concernientes a los valores tecnológicos, comportamiento y usos preliminares de 31 especies forestales tropicales desconocidas en el mercado. La toma de datos y el análisis correspondiente a las características y propiedades de la madera, se las realizó en el laboratorio de Anatomía y Tecnología de Madera de la Facultad de Ingeniería Forestal-Universidad Nacional de la Amazonía Peruana.

Se presenta el comportamiento tecnológico de la madera durante el aserrío, secado, durabilidad natural, preservado, trabajabilidad y resistencia mecánica, además 16 aplicaciones diferentes como alternativa de utilización de las especies consideradas en el estudio.

\section{INTRODUCCION}

La facultad de Ingeniería Forestal de la UNAP, dentro de su política de desarrollo, ha elaborado planes y programas de investigación, abarcando dentro de ella el área de tecnología de la madera, tendientes a determinar los usos de nuevas especies forestales tropicales de la Amazonía. El estudio abarca la investigación básica sobre descripción de la estructura celular, propiedades físicas y mecánicas, comportamiento durante el secado, aserrío, trabajabilidad, preservado, resistencia mecánica, fabricación de pulpa y papel etc. Todo ello dirigido a determinar su uso definitivo y así satisfacer la gran demanda de materia prima que requiere la Industria Forestal en nuestra región.

* Trabajo sustentado en el Seminario "Utilización industrial de Nuevas Especies Forestales".Convenio Proyecto ITTO-UNAP. Noviembre 1992 - Iquitos.

** Profesor Principal de la Facultad de Ingeniería Forestal-UNAP. Apartado Posta 120 telefax 23-4141. Iquitos-Perú. 
En esta oportunidad, la Facultad de Ingeniería Forestal en convenio con el proyecto forestal ITTO y por intermedio de la Cámara Forestal Nacional, presenta los resultados concernientes a los datos tecnológicos y usos preliminares de la madera de 31 especies forestales desconocidas en el mercado nacional e internacional, esperando tener una respuesta positiva de los usuarios de la madera.

\section{REVISION DE LITERATURA}

Según informaciones del Proyecto ITTO 37/88 "Utilización Industrial de nuevas especies forestales en la región-Fase I" (1991), ejecutado desde abril de 1990 hasta octubre de 1991, con la participación de empresas e instituciones de las ciudades de Iquitos, Pucallpa y Lima, éste ha tenido los siguientes objetivos: incorporar a la utilización industrial nuevas especies forestales de uso potencial y de significativa presencia en los bosques tropicales del país. Desarrollar investigación aplicada en empresas calificadas de la industria maderera en aserrio, secado, preservación, fabricación de parquet, durmientes y postes. Mejorar el nivel de conocimiento tecnológico en las empresas madereras de Iquitos, Pucallpa y Lima, ello mediante cursos de capacitación industrial. Desarrollar la introducción a mercados de nuevos productos forestales mediante la comercialización de lotes en depósitos de madera.

Para el cumplimiento de estos objetivos, se seleccionó varias especies forestales, basándose en su volumen disponible en los bosques peruanos, características del tronco y las propiedades de la madera, considerándose dentro de ellas algunas especies promisorias para el manejo sostenido de los bosques secundarios. Entre los productos considerados figuran: madera aserrada (incluyendo partes y piezas para muebles y envases), madera para estructuras (vigas, viguetas, columnas, correas, entablados, marcos para puertas y ventanas; etc.), pisos, durmientes y molduras. Las especies procesadas provinieron del área cercana a la carretera Tournavista (Ucayali y Huánuco) y de los kms. 60, 68 y 75: carretera Federico Basadre (Ucayali) y de la cuenca del río Nanay (IquitosLoreto). El proyecto reportó algunos resultados relevantes como por ejemplo: la capirona fue una de las especies que destacó, entre otras características favorables, por su coloración uniforme y facilidad de aserrio; a pesar de su elevada densidad, no tuvo problemas en el secado para piezas de pequeño espesor y longitud, alta resistencia al clavado. La yacushapana, como el shihuahuaco, son de difícil aserrío, buena durabilidad natural, buen comportamiento al secado y pueden servir, para la producción de durmientes, pisos, construcción, entre otros usos. Por otro lado, el agua masha es fácil de aserrar en trozas frescas, fácil de secar. El estoraque es una especie difícil de aserrar 
debido a su dureza, el secado al horno no es difícil, y es resistente al ataque de hongos.

En Iquitos, en el Centro de investigación de Puerto Almendras de ha Facultad de Ingeniería Forestal-UNAP, durante la investigación tecnológica aplicada; se encontró que el cedrillo es fácil de aserrar y muy estable; durante el secado al aire sólo se detectaron pequeñas rajaduras en los extremos de las tablas. La quillosisa, igualmente fue de fácil aserrío, pero presenta algunos problemas de secado; el mari mari, a pesar de ser una madera dura, no tiene problemas de aserrío, tiene buena trabajabilidad y no presenta defectos durante el secado al aire. La andiroha fue fácil de aserrar, el color de su madera es similar a la coba, y es resistente al ataque biológico. La huamansamana es una madera muy liviana y sensible a la mancha azul. El azúcar huayo fue la especie de más difícil aserrío, desafila rápidamente los elementos cortantes y calienta fuertemente la cinta.

Con respecto a estudios tecnológicos de la madera de especies tropicales, se encontró datos que sirvieron para reforzar los resultados del presente trabajo, Begazo y Aróstegui (1985) efectuaron la descripción anatómica a nivel general macroscopico y rnicroscópido de la madera y elaboraron claves de identificación en las siguientes especies: tahuarí, andiroha, azúcar huayo, capirona de altura. Valderrama y otros (1989), al mismo nivel de estudio anatómico, presentan información de las especies: shiningarana, punga, huamansamana. La Junta del Acuerdo de cartagena (1981), describe anatómicamente a nivel macro y, microscópico y, además, presenta los valores de las propiedades físicas y mecánicas de las siguientes especies: ojé rosado, capirona, mashonaste, estoraque, punga, panguana, andiroba, yacushapana.

Aróstegui (1976), a nivel preliminar, realizó el estudio de la distribución ecológica, descripción del árbol, descripción de la madera, propiedades físicas y mecánicas, usos probables y, en algunos casos, determinó la aptitud papelera y propiedades de durabilidad y preservación de las siguientes especies: huamansamana, carahuasca, andiroha, azúcar huayo, pashaco blanco, ubos, ojé rosado, cachimbo, requia, huayruro, manchinga, pumaquiro, yacushapana, capirona, estoraque, shihuahuaco, tahuarí y mashonaste.

Loureiro y Freitas (1968), presentan datos a nivel dendrológico, distribución geográfica, hábitat, características generales de la madera, descripción macroscópica y usos comunes de las siguientes especies: andiroha, mashonaste, cedrillo, pashaco colorado, huamansamana, punga. Aróstegui (1982), haciendo una recopilación de información de estudios tecnológicos de maderas peruanas, informa sobre las características anatómicas de la madera, propiedades físicas y mecánicas, trabajabilidad y usos de la madera de las siguientes especies: azúcar huayo, punga, pashaco blanco, ubos, hualaja, 
panguana, huayruro, machinga, pumaquiro, yacushapana, estoraque, tahuarí, mashonaste.

Valderrama (1991), presenta los valores de las propiedades físicas (peso específico, contenido de humedad, contracción), determinados en el laboratorio de Anatomía y Tecnología de la Madera de la Facultad de Ingeniería Forestal de la UNAP, de las siguientes especies: pashaco colorado, pashaco blanco, cedrillo, quillosisa, azúcar huayo, mari mari, shiringarana, carahuasca negra, maría buena.

El comportamiento tecnológico de la madera, se determinó mediante relación de la estructura celular y propiedades. Aróstegui y Valderrama (1986), emplearon un sistema de investigación y procedimiento menos costoso, más sencillo y práctico que, sin remplazar al tradicional, posibilita estimar simultáneamente los usos probables de la madera de un gran número de especies forestales, basándose en los caracteres anatómicos importantes (color, grano, textura, veteado, inclusiones; etc.), propiedades físicas (peso específico, contenido de humedad, contracción), relacionados con el comportamiento de la madera durante el secado, preservado resistencia mecánica, trabajabilidad; entre otros y evaluadas a partir de muestras pequeñas del árbol. Valderrama (1992), analiza la relación que existe entre la estructura anatómica con el comportamiento tecnológico de la madera de treinta especies forestales de la Amazonía Peniana, relaciona caracteres anatómicos como: fibras, vasos, dirección del grano, contenido; etc. con el comportamiento tecnológico de la madera: secado, preservado, resistencia mecánica, trabajabilidad, fabricación de pulpa y papel; etc. El mismo autor (1984), realizó el estudio de correlación entre el peso específico y las propiedades mecánicas, estas formulaciones poseen cierto grado de aceptabilidad a raíz del alto coeficiente de correlación entre las variables, lo que facilita la estimación de las propiedades mecánicas en función a la densidad básica de la madera.

\section{MATERIALES Y MÉTODO}

El trabajo se desarrolló en el laboratorio de Anatomía y Tecnología de la Madera de la Facultad de Ingeniería Forestal de la Universidad Nacional de la Amazonía Peruana. Los materiales utilizados, corresponden a muestras de madera para los diferentes ensayos, se las realizó en coordinación con las actividades del proyecto ITTO PD 37/3 8 (cuadro 1).

Los datos obtenidos en campo y en laboratorio se traducen en características de la troza (calidad, diámetro, flotación, ataques biológicos), características organolépticas de la madera (diferenciación entre albura, 
porcentaje de albura, color, brillo, grano, veteado, textura, olor y sabor), propiedades físicas (contenido de humedad, peso específico, contracción), valores estimados de las propiedades mecánicas (flexión estática, compresión paralela y perpendicular, dureza, cizallamiento, tenacidad). Existen grupos de especies estudiadas por autores como: Aróstegui (1976, 1986, 1982, 1980-81). Aróstegui y Sato (1970). Aróstegui y Valderrama (1986). Acevedo y Santillana (1991). Begazo y Aróstegui (1985). Chichignoud (1990). Informes de la ITTO (1991), JUNAC (1991), Valderrama (1989, 1984, 1986, 1991, 1992), Vander Sloten (1981), que pertenecen al grupo de especies seleccionadas en el presente estudio. La recopilación bibliográfica sobre las propiedades tecnológicas ha servido como base para complementar el resultado obtenido y mediante su análisis se definió el comportamiento tecnológico de la madera durante la trabajabilidad con máquinas de carpintería, resistencia mecánica, aserrío, secado, durabilidad natural, tratamiento preservador y USOS probables de la madera por cada especie.

\section{RESULTADOS Y DISCUSIONES}

En el cuadro 2, observamos que la mayoría de trozas son regulares en cuanto a calidad, existen trozas irregulares por los múltiples defectos que presentan en relación a su forma, entre estas especies se considera al ubos, maría buena, requia. Respecto al diámetro, la mayoría de trozas evaluadas se categoriza como medianas, que es muy importante para el aprovechamiento de la especie por su madera. Las especies como el mari mari, ojé rosado; probablemente tengan limitaciones para el aserrío, en aserraderos que no tienen la capacidad para aserrar trozos con 3diámetros pronunciados. Por lo general las maderas duras no flotan, lo que limita el transporte por flotación; es conveniente al momento de emboyarlos, asociarlos con especies blandas que sirven como flotadores. Algunas especies como cedrillo, quillosis flotan poco tiempo o los primeros días después del emboyado, luego se sumergen; originando grandes pérdidas económicas al usuario, es recomendable asociarlos con maderas blandas durante el emboyado.

Existen grupos de especies que son fácilmente atacados por agentes biológicos (hongos, insectos), generalmente entre el almacenamiento y el aserrío, de ellos se puede citar: pashacco colorado, huamansamana, maría buena, punga, pashaco blanco, ubos, hualaja, panguaja; etc., se debe buscar el método de tratamiento apropiado para evitar estos ataques de descalifican la madera procesada; o, en todo caso, aserrarlas inmediatamente después del talado. Otras especies poseen ataques sólo en albura, tales como mari mari y mashonaste, mientras que las especies de cedrillo, quillosisa, tahuarí tienen médula hueca, y 
en aquellas con mucho tiempo de almacenamiento se noto ataques como en ana caspi. Las características negativas en la troza, originaron un decremento del rendimiento de aserrío y, en consecuencia, pérdida económica para el usuario. Existen trozas con características muy buenas que generan aumento del rendimiento de aserrío, (cuadro 2).

En el cuadro 3, se observa las características organolépticas de la madera; notándose que la mayoría de especies posee albura y duramen diferenciado, el porcentaje de albura varía notablemente de una especie a otra; desde aproximadamente $10 \%$ como en el estoraque, pumaquiro; hasta $80 \%$ como en yacushapana, esta diferenciación del xilema origina diferentes tonalidades de color y veteados en las secciones longitudinales de la madera. La andiroba posee albura de color pardo y duramen pardo rojizo; con diferentes tonalidades y veteado llamativo, a diferencia de la punga que no posee albura y duramen diferenciado. La coloración se limita al amarillo crema, veteado no definido, descalificando la madera por su color y figura no llamativo. Existen maderas que poseen brillo bajo, entre ellas: shiringanara, punga, requia, shihuahuaco, tahuarí, originando el acabado deficiente de la madera; sin embargo especies como el ubos, mari mari, ojé rosado, ojé blanco, hualaja; entre otros, tienen brillo elevado con mejor acabado de las caras longitudinales. El brillo es una característica que con aplicación de barnices, lacas y otros productos químicos, se mejoraría la calidad de la madera. Con respecto a la textura, las especies fueron calificadas desde gruesa (pashaco colorado, punga, huayro) hasta maderas con textura fina (requia, machinga, capirona, estoraque, shihuahuaco, tahuarí, esta característica actúa como indicador de la densidad y otras propiedades importantes de uso de la madera.

El cuadro 4, consigna las propiedades físicas de la madera. Respecto a la densidad básica, la mayoría de especies $(45.16 \%)$, está comprendida dentro del rango 0.41-0.60 $\mathrm{gr} / \mathrm{cm}^{3}$ clasificada con densidad media; asimismo. el $48.39 \%$ de especies está clasificado de contracción volumétrica total media $(10.1 \%-13 \%)$, estable en mayoría (58.06\%). Este grupo de especies se caracteriza por su buen comportamiento al trabajo con máquinas de carpintería, regular en cuanto a sus propiedades de contracción, resistencia mecánica y durabilidad, también fácilmente se puede elevar la durabilidad, por su buen comportamiento a la retención de productos químicos, en este grupo de especies tenemos: pashaco colorado, cedrillo, quillosisa, andiroba, mari mari, pashaco blanco, cachimbo requia, mashonaste. Las maderas con densidad alta, por lo general poseen textura fina, propiedades de contracción de regular a mala, resistencia mecánica alta; especialmente en flexión estática, comprensión, cizallamiento y dureza, durabilidad natural de regular a buena, en este grupo se consideran las siguientes 
especies: azúcar huayo, huayruro, manchinga, pumaquiro, yacushapana, ana caspi. Las maderas con densidad muy alta como: capirona, estoraque, shihuahuaco y tahuari, poseen buena resistencia mecánica y alta durabilidad.

En el cuadro 5, se observa las propiedades mecánicas. Estos valores en especies como maría buena, carahuasca, cedrillo, quillosisa, mari mari, punga, ojé renaco, fueron estimados en relación a los valores de la densidad básica, aplicando las formulaciones de regresión y correlación encontrados por Valderrama (1984), estas estimaciones fueron correlacionadas con otras características de la madera, lo que permitió definir el comportamiento tecnológico y usos de la madera. Las propiedades mecánicas de las demás especies, responden a informaciones recopiladas de material bibliográfico existente. En felxión estática (EFLP), las especies capirona, estoraque, andiroba, pumaquiro, mashonaste, soportan cargas por encima de los $600 \mathrm{~kg} / \mathrm{cm}^{2}$, con módulo de elasticidad mayor de los $120,000 \mathrm{~kg} / \mathrm{ccm}^{2}$ y cargas totales en módulo de ruptura superiores a $\operatorname{los} 900 \mathrm{~kg} / \mathrm{cm}^{2}$ calificadas de resistencia alta, estas especies probablemente tienen aplicaciones en vigas de las construcciones de viviendas y en otros usos donde el material esta sujeto a cargas similares. Asimismo, las especies azúcar huayo, tahuarí, mashinaste, shihuahuaco, estoraque, capirona, yacushapana, pumaquiro, ana caspi, soportan cargas en comprensión paralela por encima de $\operatorname{los} 400 \mathrm{~kg} / \mathrm{cm}^{2}$, calificados de resistencia alta, la madera de estas especies puede ser utilizada en columnas, pilotes, puntales; entre otros miembros estructurales de la construcción pesada y de viviendas. La madera de capirona, estoraque, shihuahuaco, tahuarí, mashonaste supera los $100 \mathrm{~kg} / \mathrm{cm}^{2}$ en compresión perpendicular, calificándola de alta a muy alta en cuanto a su resistencia, característica muy importante de la madera; juntamente es la durabilidad elevada, que la hace apta para ser utilizada como durmientes. Respecto a la dureza, son las especies de mayor densidad las que soportan cargas superiores a los $1000 \mathrm{~kg} / \mathrm{cm}^{2}$, dentro de este grupo de especies están: capirona, estoraque, shihuahuaco, tahuarí. Las especies que soportan cargas elevadas en cizallamiento, tienen buena resistencia en uniones estructurales, piezas ensambladas; etc., entre estas especies podemos recomendar: azúcar huayo, huayruro, manchinga, pumaquiro, yacushapana, capirona, estoraque, shihuahuaco, tahuarí, mashonaste. Especies como: shihuahuaco, tahuarí, pumaquiro, yacushapana, capirona; poseen resistencia muy alta al impacto o golpe, se recomienda utilizar estas maderas, en piezas estructurales sujetas a este tipo de esfuerzo.

En los cuadro del 6 al 11, se observa los resultados del comportamiento tecnológico y usos de la madera por especie: aserrío, secado, durabilidad natural, tratamiento preservador, trabajabilidad, resistencia mecánica. El comportamiento 
de las maderas durante el aserrio, se clasificaron como: malo, regular y bueno. En general aquellas maderas con densidad media a muy baja, no tiene problemas durante el aserrío, con excepción del pashaco colorado, que presenta reventamientos durante su aserrío, originado en gran parte por las tensiones internas en la troza. Las especies con densidad alta a muy alta poseen comportamiento de regular a malo con excepción del huayruro y pumaquiro, que aparentemente no tienen problemas de aserrio. Las especies con problemas de aserrío, probablemente poseen sílice en la estructura celular, que desafilan rápidamente las sierras y cuchillos de las maquinarias, originando mayores costos de producción; en consecuencia, se recomienda usar sierras apropiadas con un sistema de afilado eficiente para el corte.

Las variables utilizadas para calificar el comportamiento de la madera durante el secado fueron: contracción, estabilidad y defectos físicos. Encontrándose grupos de especies como: pashaco blanco, quillosisa, azúcar huayo, punga; que probablemente tiene mal comportamiento al secado. Sin embargo, se prevé buen comportamiento de secado en: huamansamana, carahuasca, andiroha, mari mari, hualaja, panguana, cachimbo blanco, cachimbo, requia, huayruro, ppumaquiro, yacushapana, estoraque, shihuahuaco.

Respecto a la durabilidad natural, las maderas blandas, susceptibles al ataque de hongos e insectos como : pashaco colorado, ojé renaco, hualaja, manchinga, requieren tratamiento preservador; dentro de este grupo de especies también están aquellas que moderadamente son resistentes en condición seca, y aquellas que en condición verde presentan ataques en las capas superficiales (insectos). Sin embargo, las maderas muy densas, probablemente por su elevada durabilidad natural, no requieren tratamiento preservador; entre estas especies podemos citar: azúcar huayo, pumaquiro, yacushapana, ana caspi, capirona, estoraque, shihuahuaco, tahuarí. Las especies, huayryro y manchinga, a pesar de ser maderas duras, tienen problemas por ataques biológicos; en consecuencia, es recomendable preservarlos antes de utilizarlos.

El comportamiento durante la trabajabilidad de la madera, especialmente con máquinas de carpintería, se lo analizó mediante la relación existente entre la densidad, grano, contenido, dureza, textura entre otras características. Las especies: maría buena, huamansamana, cedrillo, andiroha, hualaja, cachimbo blanco, requia, tienen buen comportamiento; generalmente se debe a que la madera tiene densidad media pocas células parenquimatosas, grano recto ligeramente inclinado, sin sílice en las células, dureza de media a baja, compuestos orgánicos (aceites); que dan brillo a la madera; entre otras características. Las maderas que tiene mal comportamiento al ser trabajadas con 
máquinas de carpintería, poseen características diferentes al grupo de especies anteriormente mencionadas y que descalifican la calidad del acabado; entre estas especies tenemos: punga y huayruro.

Existen grupos de especies calificadas con comportamiento regular que, por lo general, son aquellas maderas de densidad alta a muy alta como: tahuarí, shihuahuaco, estoraque, capirona, ana caspi, yacushapana, pumaquiro, manchinga; éstas originan problemas de desafilado de sierras y cuchillos. Respecto a la resistencia mecánica, las maderas con mayor densidad, se clasifican de alta a muy alta, y las que tienen densidad baja presentan resistencia mecánica de baja a muy baja.

En análisis presentado para definir el comportamiento tecnológico y usos de la madera, responde a ciertas aproximaciones, basadas en las características anatómicas y propiedades evaluadas en el laboratorio. Sin embargo, con la finalidad de brindar al usuario valores con mayor confiabilidad, es conveniente reforzar la información Con resultados encontrados mediante la investigación aplicada, que permita recomendar con mayor exactitud los usos y el comportamiento tecnológico definitivo de la madera, para las especies que se presentan en esta oportunidad.

\section{CONCLUSIONES Y RECOMENDACIONES}

a. Los resultados encontrados, responden al análisis de datos, basados en características anatómicas, propiedades físicas y mecánicas de la madera, transporte de trozas, aserrío, secado y ataques biológicos en troza y madera aserrada.

b. Se recomienda utilizar las especies en base a los resultados obtenidos; sin embargo, el comportamiento tecnológico y usos de la madera que presentamos pueden ser considerados como resultados preliminares; y su aplicación responde a ciertos criterios técnicos del usuario.

e. Reforzar los resultados obtenidos, con mayores estudios tecnológicos propiciar el uso definitivo de estas especies. 


\section{BIBLIOGRAFIA}

AROSTEGUI, A. 1976. Características tecnológicas y usos de la madera de 145 especies del país. Vol. 1. Ministerio de Agricultura. Dirección General de Investigación-Universidad Nacional Agraria La Molina. Lima-Perú 472 p.

-------1980-1981. "Propiedades tecnológicas y uso de la madera de 40 especies del Bosque Nacional Alexander Von Hwnboldt", en Revista Forestal del Perú. Vol. X No 1-2. Lima-Perú 3-82 p.

-------1982. "Recopilación y análisis de estudios tecnológicos de maderas peruanas". Documento de trabajo $\mathrm{N}^{\mathrm{o}}$ 2, Proyecto $\mathrm{PNUD} /-$ FAO/PER/81/002. Lima-Perú 57 p.

------ y A. SATO. 1970. "Propiedades físicomecánicas de la madera de 16 especies forestales del Perú, en Revista Forestal del Perú. Vol. 4 No 1-2. Lima-Perú. 13-24 p.

y M. SOBRAL. 1986. “Avance técnico del Proyecto Usos de la Madera del Bosque Húmedo Tropical Colonia Angamos, Río Yavarí y Jenaro Herrera”. Convenio INAP-IIAP-UNAP. Iquitos- Perú, 14 p.

y H. VALDERRAMA 1986. "Usos probables de la madera de diez especies forestales del Bosque Húmedo Tropical Allahuayo". Iquitos. Convenio IIAP-UNAP. 31 P.

ACEVEDO, M. y J. SANTILLANA. 1991. "Descripción anatómica y clave de identificación de 19 especies forestales de Madre de Dios", en Revista Forestal del Perú 18 (2). Lima-Perú. 5-16 p.

BEGAZO, N. y A. AROSTEGUI. 1985. "Estructura anatómica y clave de identificación de 20 especies forestales de Iquitos”, en Revista Forestal del Perú. Vol. XIII, No 1 . Lima-Perú. 3-22 p.

CHICHIGNOUD, M. et al. 1990. Atlas de maderas tropicales de América Latina. Association Technique Internacionale des Bois Tropicanx. Francis, $218 \mathrm{p}$. 
I.T.T.O. 1991. "Utilización industrial de nuevas especies forestales en el Perú. Fase I. Cámara Nacional Forestal. Dirección General Forestal y Fauna. Proyecto ITTO PD/37/88. Lima-Perú. 46,58,8- 3,93.

JUNAC. 1982. “Tablas de propiedades físicas y mecánicas de la madera de 20 especies del Perú”. PADT-REFORT. Grupo Andino. Lima-Perú. 53 p.

------ 1991. "Descripción general y anatómica de 105 maderas del Grupo Andino". PADTT-REFORT. Grupo Andino. Cali Colombia. 442 p.

VALDERRAMA, H. 1984. "Estudio de las propiedades físicas y su variación en el tronco de la Tachigalia liongiflora D. y Sclerolobium melinonii H., en Puerto Almendra Iquitos". Tesis para optar el título de ingeniero Forestal. UNAP. Iquitos. Perú 92 p.

1986. "Estructura anatómica de la madera de 10 especies forestales de Selva Baja". Proyecto Convenio IIAP-UNAP. Documento de trabajo $\mathrm{N}^{\mathrm{o}}$ 044-87/DIT. Iquitos-Perú. 50 pp.

-------, et al 1989. "Estructura anatómica y clave de identificación de veinte especies forestales de la zona de Colonia Angamos”, Río Yavarí y Jenaro Herrera. UNAP-Facultad de Ingeniería Forestal. IIAPP, INPA-Manaos. Iquitos-Perú. $130 \mathrm{p}$.

------- H. 1991. "Tabla de valores de las propiedades físicas de especies estudiadas en el Proyecto Forestal ITTO". Laboratorio de Anatomía y Tecnología de la madera. FIF-UNAP. Iquitos-Perú. 3 pp.

H. 1992. "Influencia de la estructura anatómica en el comportamiento tecnológico de treinta especies forestales de la Amazonía Peruana". Facultad de Ingeniería Forestal. UNAP. Iquitos-Perú. 16 p.

VAN DER SLOOTEN, H. et al 1981. Madeiras da Amazonia. Vol. I. Floresta nacional do Tapajos. IBDF-CNPq. Brasil. 113 p. 


\section{Cuadro 1}

\section{ESPECIES CONSIDERADAS}

Familia

1. Pashaco colorado

2. María buena

3. Huamanzamana

4. Carahuarca

5. Shiringarana

6. Cedrillo

7. Quillosisa

8. Andiroba

9. Mari mari

10. Azúcar huayo

11. Punga

12. Pashaco blanco

13. Ubos

14. Ojé blanco

15 Ojé rosado

16. Ojé renaco

17. Hualaja

18. Panguana

19. Cachimbo blanco

20. Cachimbo

21. Requia

22. Huayruro

23. Machinga

24. Pumaquiro

25. Yacushapana

26. Capirona

27. Estoraque

28. Shihuahuaco

29. Tahuarí

30. Mashonaste

31. Ana caspi
Macrobrachiumaceceineifolium Benth

Pterocarpus amazoniens Mart

Jacaranda copaia

Guatteria hyposericeae

Micranda spruceana

Vochisia vismifolia spruceana

Erisma bicolor Ducke

Carapa guianensis

Hymenolobium sp.

Hymeneae oblongifolia

Pseudobombax munguuba $M$.

albizzia sp.

Spondias mombin 1.

Ficus insipida

Ficus glabrata

Ficus sp.

Zanthoxrylum sp.

Brosium utile (N .B. K) Pitt

Cariniana decandra

Cariniana sp.

Guarea gomma

Ormosia sp

Brosium uleanum s .w

Aspidosperma macrocarpon

Terminalia amazónica

Calvcophillum spruceanum

Myroxylon balsamum

Coumarouma odorata

Tabebuia serratifolia

Clarisia racemosa

Apuleia molaris
Leguminosae

Leguminosae

Bignonaceae

Annonaceae

Euphorbiaceae

Vochysiaceae

Vochysiaceae

Meliaceae

Leguminosae

Leguminosae

Bombacaceae

Leguminosae

Anacardiaceae

Moraceae

Moraceae

Moraceae

Rutaceae

Moraceae

Lecythidaceae

Lecythidaceae

Maliaceae

Leguminosae

Moraceae

Apocynaceae

Combretaceae

Rubiaceae

Leguminosa

Leguminosa

Bignonaceae

Moraceae

Legumonosae 


\section{Cuadro 2}

\section{CARACTERISTICAS DE LAS TROZAS}

\begin{tabular}{|c|c|c|c|c|c|}
\hline $\mathrm{N}^{\mathrm{o}}$ & ESPECIE & $\begin{array}{l}\text { CALIDAD } \\
\text { TROZA }\end{array}$ & DIAMETRO & FLOTAN & $\begin{array}{l}\text { ATAQUES } \\
\text { BIOLOGICOS }\end{array}$ \\
\hline 1. & Pashaco colorado & Irreg/defect & Mediano & sí & sí \\
\hline 2. & María buena & Mala & Mediano & sí & sí \\
\hline 3. & Huamanzamana & Regular & Pequeño & sí & sí \\
\hline 4. & Carahuarca & Irreg/defect & Pequeño & sí & Termites \\
\hline 5. & Shiringarana & Regular & Peque-media & sí & no \\
\hline 6. & Cedrillo & Regular & Pequeño & no $(*)$ & Med.hueca(*) \\
\hline 7. & Quillosisa & Regular & Mediano & no $(*)$ & Med.ataca $(* *)$ \\
\hline 8. & Andiroba & Regular & Media-grand. & --- & no \\
\hline 9. & Mari mari & Regular & Pequeños & no & ataques (alb) \\
\hline 10. & Azúcar huayo & Regular & Media-grand. & No & no \\
\hline 11. & Punga & Regular & Mediano & sí & sí \\
\hline 12. & Pashaco blanco & Regular & Mediano & sí & sí \\
\hline 13. & Ubos & Mala & Mediano & sí & sí \\
\hline 14. & Ojé blanco & Regular & Mediano & sí & Hongos \\
\hline 15 & Ojé rosado & Regular & Med-grand & sí & Hongos \\
\hline 16. & Ojé renaco & Regular & Med-grand & sí & Hongos \\
\hline 17. & Hualaja & Regular & Mediano & sí & sí \\
\hline 18. & Panguana & Regular & Med-grand. & --- & sí \\
\hline 19. & Cachimbo blanco & Regular & Peque-media & sí & Ataques leves \\
\hline 20. & Cachimbo & Regular & Media-grande & sí & Ataques leves \\
\hline 21. & Requia & Mala & Mediano & --- & no \\
\hline 22. & Huayruro & Regular & Media-grande & no & Resistente \\
\hline 23. & Machinga & Regul-irreg & Mediano & no & sí \\
\hline 24. & Pumaquiro & Regular & Mediano & no & Orif.médula \\
\hline 25. & Yacushapana & Regul-irreg & Mediano & no & no \\
\hline 26. & Capirona & Regular & Mediano & no & no \\
\hline 27. & Estoraque & Regular & Pequeño & no & no \\
\hline 28. & Shihuahuaco & Regular & Media-grande & no & Hongos (alb) \\
\hline 29. & Tahuarí & Regular & Peque-media & no & Ataq-méd.(**) \\
\hline 30. & Mashonaste & Regular & Mediano & no & Ataq. (avl.) \\
\hline 31. & Ana caspi & Regular & Mediano & no & Ataques $(* * *)$ \\
\hline
\end{tabular}

\footnotetext{
* $\quad$ Flotan poco tiempo o los primeros días después del emboyado y se precipitan

$* * \quad=$ En algunas trozas

$* * *$ Ataques con mucho tiempo de almacenamiento.
} 
Cuadro 3

CARACTERISTICAS ORGANOLÉPTICAS DE LA MADERA

\begin{tabular}{|c|c|c|c|c|c|c|c|c|c|c|}
\hline $\mathrm{N}^{\mathrm{o}}$ & ESPECIE & $\begin{array}{l}\text { Diferenciación } \\
\text { alb. y duram. }\end{array}$ & $\begin{array}{l}\text { (\%) de } \\
\text { albura }\end{array}$ & $\begin{array}{l}\text { Color }(*) \\
\text { Albura }\end{array}$ & Duramen & Brillo & Grano & Veteado & textura & $\begin{array}{l}\text { Olor y } \\
\text { sabor }\end{array}$ \\
\hline 1 & Pashaco colorado & Diferenciado & 40 & $\begin{array}{l}\text { Pardo } \\
\text { Rojizo }\end{array}$ & $\begin{array}{l}\text { Rojizo dif. } \\
\text { tonalidades }\end{array}$ & $\begin{array}{l}\text { Medio a } \\
\text { bajo }\end{array}$ & $\begin{array}{l}\text { Entrecruzado } \\
\text { a recto }\end{array}$ & $\begin{array}{l}\text { Levemente } \\
\text { jaspeado }\end{array}$ & $\begin{array}{l}\text { Gruesa } \\
\text { a media }\end{array}$ & Ausente \\
\hline 2 & María buena & ------- & --- & Amarillo & crema (xilema) & Medio & Recto & No diferen. & Media & Ausente \\
\hline 3 & Huamansamana & No diferencia & --- & Blanco-rosado & (xilema) & Medio & Recto & Jaspeado & Media & Ausente \\
\hline 4 & Carahuasca & Diferenciado & --- & Pardo & Rojo & Medio & Recto & $\begin{array}{l}\text { Bandas } \\
\text { paralelas }\end{array}$ & $\begin{array}{l}\text { Gruesa a } \\
\text { media }\end{array}$ & Ausente \\
\hline 6 & Cedrillo & Levem.diferen. & --- & Pardo rojizo & (xilema) & Medio & $\begin{array}{l}\text { Oblicuo a } \\
\text { entrecruzado }\end{array}$ & $\begin{array}{l}\text { Levem.jaspeado } \\
\text { bandas paral. }\end{array}$ & Media & Ausente \\
\hline 7 & Quillosisa & Diferenciado & 26 & Amarillo & $\begin{array}{l}\text { Pardo } \\
\text { rojizo }\end{array}$ & $\begin{array}{l}\text { Medio a } \\
\text { bajo }\end{array}$ & $\begin{array}{l}\text { Oblicuo a } \\
\text { entrecruzado }\end{array}$ & $\begin{array}{l}\text { Levemente } \\
\text { jaspeado }\end{array}$ & Media & Ausente \\
\hline 8 & Andiroba & Diferenciado & --- & $\begin{array}{l}\text { Pardo } \\
\text { grisáceo }\end{array}$ & $\begin{array}{l}\text { Pardo } \\
\text { rojizo }\end{array}$ & Medio & $\begin{array}{l}\text { Recto a } \\
\text { entrecruzado }\end{array}$ & $\begin{array}{l}\text { Arcos super. } \\
\text { caracterís. }\end{array}$ & Media & Ausente \\
\hline 9 & Mari mari & Diferenciado & 28 & $\begin{array}{l}\text { Amarillo } \\
\text { pardo }\end{array}$ & $\begin{array}{l}\text { Amarillo } \\
\text { pardo }\end{array}$ & Elevado & Entrecruzado & $\begin{array}{l}\text { Lineas irreg. } \\
\text { jaspeado }\end{array}$ & $\begin{array}{l}\text { Media a } \\
\text { fina }\end{array}$ & Ausente \\
\hline 10 & Azúcar huayo & Diferenciado & --- & $\begin{array}{l}\text { Blanco } \\
\text { rosado }\end{array}$ & Pardo rojo & Medio & $\begin{array}{l}\text { Recto a } \\
\text { entrecruzado }\end{array}$ & $\begin{array}{l}\text { Arcos superp. } \\
\text { satinado.b.p }\end{array}$ & Media & Ausente \\
\hline 11 & Punga & No diferenc. & --- & Amarillo & (xilema) & Bajo & Recto & No definido & Gruesa & Ausente \\
\hline 12 & Pashaco blanco & Diferenciado & --- & Crema & Rojizo & Medio & Entrecruzado & $\begin{array}{l}\text { Arcos super. } \\
\text { bandas paral. }\end{array}$ & $\begin{array}{l}\text { Media a } \\
\text { gruesa }\end{array}$ & Ausente \\
\hline 13 & Ubos & Diferenciado & --- & Blanco & Blanco & Elevado & Recto & $\begin{array}{l}\text { Arcos superp. } \\
\text { bandas paral. }\end{array}$ & Media & Ausente \\
\hline 14 & Ojé blanco & No diferenciado & --- & Amarillo & (xilema) & Elevado & Recto a oblic. & Arcos super. & Media & Ausente \\
\hline 15 & Ojé rosado & Lig. diferenc. & --- & $\begin{array}{l}\text { Amarillo } \\
\text { pálido }\end{array}$ & Rojizo & Elevado & $\begin{array}{l}\text { Oblicuo a } \\
\text { entrecruzado }\end{array}$ & $\begin{array}{l}\text { Arcos super. } \\
\text { satinado b.p. }\end{array}$ & Media & Ausente \\
\hline 16 & Ojé renaco & Diferenciado & --- & Crema & Amarillo & Elevado & Entrecruzado & Arcos super. & Media & Ausente \\
\hline 17 & Hualaja & Lev. jaspeado & --- & Amarillo & (xilema) & Elevado & Recto & $\begin{array}{l}\text { Arcos super. } \\
\text { Bandas paral. }\end{array}$ & Media & Ausente \\
\hline
\end{tabular}


Continuación cuadro 3

\begin{tabular}{|c|c|c|c|c|c|c|c|c|c|c|}
\hline $\mathrm{N}^{0}$ & ESPECIE & $\begin{array}{l}\text { Diferenciación } \\
\text { alb. y duram. }\end{array}$ & $\begin{array}{l}(\%) \text { de } \\
\text { albura }\end{array}$ & $\begin{array}{l}\text { Color }(*) \\
\text { Albura }\end{array}$ & Duramen & Brillo & Grano & Veteado & textura & $\begin{array}{l}\text { Olor y } \\
\text { sabor }\end{array}$ \\
\hline 18. & Panguana & Diferenciado & --- & Blanco & Rojizo & Elevado & $\begin{array}{l}\text { Recto a } \\
\text { entrecruzado }\end{array}$ & Bandas paral. & Media & Ausente \\
\hline 20 & Cashimbo & Lev. diferenciado & --- & Pardo claro & Pardo rojizo & Medio & Recto & Suave & $\begin{array}{l}\text { Fina a } \\
\text { media }\end{array}$ & Ausente \\
\hline 21 & Requia & No diferenciado & --- & Rojizo & (xilema) & Bajo & Recto & $\begin{array}{l}\text { Jaspeado,arcos } \\
\text { superp.bandas } \\
\text { paral. }\end{array}$ & Fina & $\begin{array}{l}\text { Poco } \\
\text { percept. }\end{array}$ \\
\hline 22 & Huayruro & Diferenciado & --- & $\begin{array}{l}\text { Beige } \\
\text { anaranjado }\end{array}$ & $\begin{array}{l}\text { Pardo } \\
\text { rojizo }\end{array}$ & Elevado & Entrecruzado & $\begin{array}{l}\text { Lineas vertc. } \\
\text { satinado,bandas } \\
\text { paralelas }\end{array}$ & Gruesa & $\begin{array}{l}\text { Ligerame. } \\
\text { aromático }\end{array}$ \\
\hline 23 & Manchinga & Poco diferenciado & --- & Crema & Rojizo & Elevado & Entrecruzado & Arcos superp. & Fina & Ausente \\
\hline 24 & Pumaquiro & No diferenciado & 10 & $\begin{array}{l}\text { Crema } \\
\text { pardo }\end{array}$ & $\begin{array}{l}\text { Pardo } \\
\text { amarillento }\end{array}$ & Medio & Entrecruzado & $\begin{array}{l}\text { Bandas paral. } \\
\text { rejlejos dorado }\end{array}$ & $\begin{array}{l}\text { Media a } \\
\text { fina }\end{array}$ & Ausente \\
\hline 26 & Capirona & Diferenciado & --- & Crema & $\begin{array}{l}\text { Amarillo } \\
\text { crema }\end{array}$ & Medio & $\begin{array}{l}\text { Oblicuo a } \\
\text { entrecruzado }\end{array}$ & No definido & Fina & Ausente \\
\hline 27 & Estoraque & Diferenciado & 10 & $\begin{array}{l}\text { Pardo } \\
\text { amarillento }\end{array}$ & $\begin{array}{l}\text { Pardo } \\
\text { rojizo }\end{array}$ & Elevado & $\begin{array}{l}\text { Recto a } \\
\text { entrecruzado }\end{array}$ & $\begin{array}{l}\text { Arcos superp. } \\
\text { bandas paral. }\end{array}$ & Fina & $\begin{array}{l}\text { Ligerame. } \\
\text { aromático }\end{array}$ \\
\hline 28 & Shihuahuaco & Levem. diferenciado & --- & Rojizo & (xilema) & Bajo & Entrecruzado & Arcos superp. & Fina & Ausente \\
\hline 29 & Tahuari & Diferenciado & --- & $\begin{array}{l}\text { Blanco } \\
\text { grisáceso }\end{array}$ & $\begin{array}{l}\text { Olivo } \\
\text { claro }\end{array}$ & Bajo & Entrecruzado & $\begin{array}{l}\text { Bandas paral. } \\
\text { arcos superp. }\end{array}$ & Fina & Ausente \\
\hline 30 & Mashonaste & Diferenciado & 20 & $\begin{array}{l}\text { Blanco } \\
\text { pardo }\end{array}$ & $\begin{array}{l}\text { Amarillo } \\
\text { pardo }\end{array}$ & Elevado & $\begin{array}{l}\text { Recto a } \\
\text { entrecruzado }\end{array}$ & $\begin{array}{l}\text { Jaspeado,arcos } \\
\text { super.,bandas }\end{array}$ & Media & Ausente \\
\hline 31 & Ana caspi & ------- & 30 & Amarillo & $\begin{array}{l}\text { Amarillo } \\
\text { pardo }\end{array}$ & Medio & Entrecruzado & Bandas paral. & $\begin{array}{l}\text { Fina a } \\
\text { caracteris. }\end{array}$ & $\begin{array}{l}\text { Levemente } \\
\text { mediano }\end{array}$ \\
\hline
\end{tabular}

(*) = Condición seco al aire. 


\section{Cuadro 4}

\section{PROPIEDADES FÍSICAS}

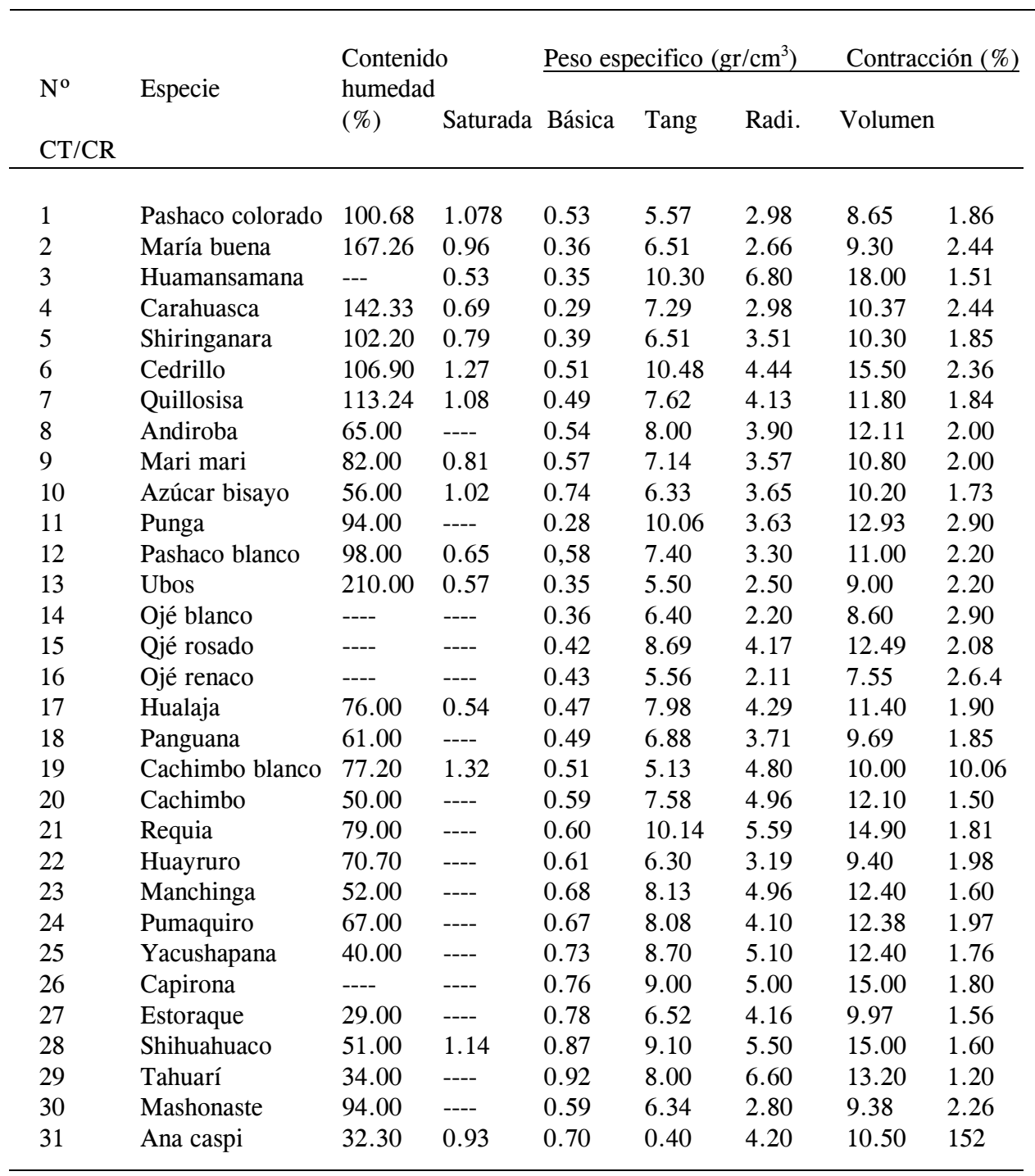




\section{Cuadro 5}

PROPIEDADES MECÁNICAS

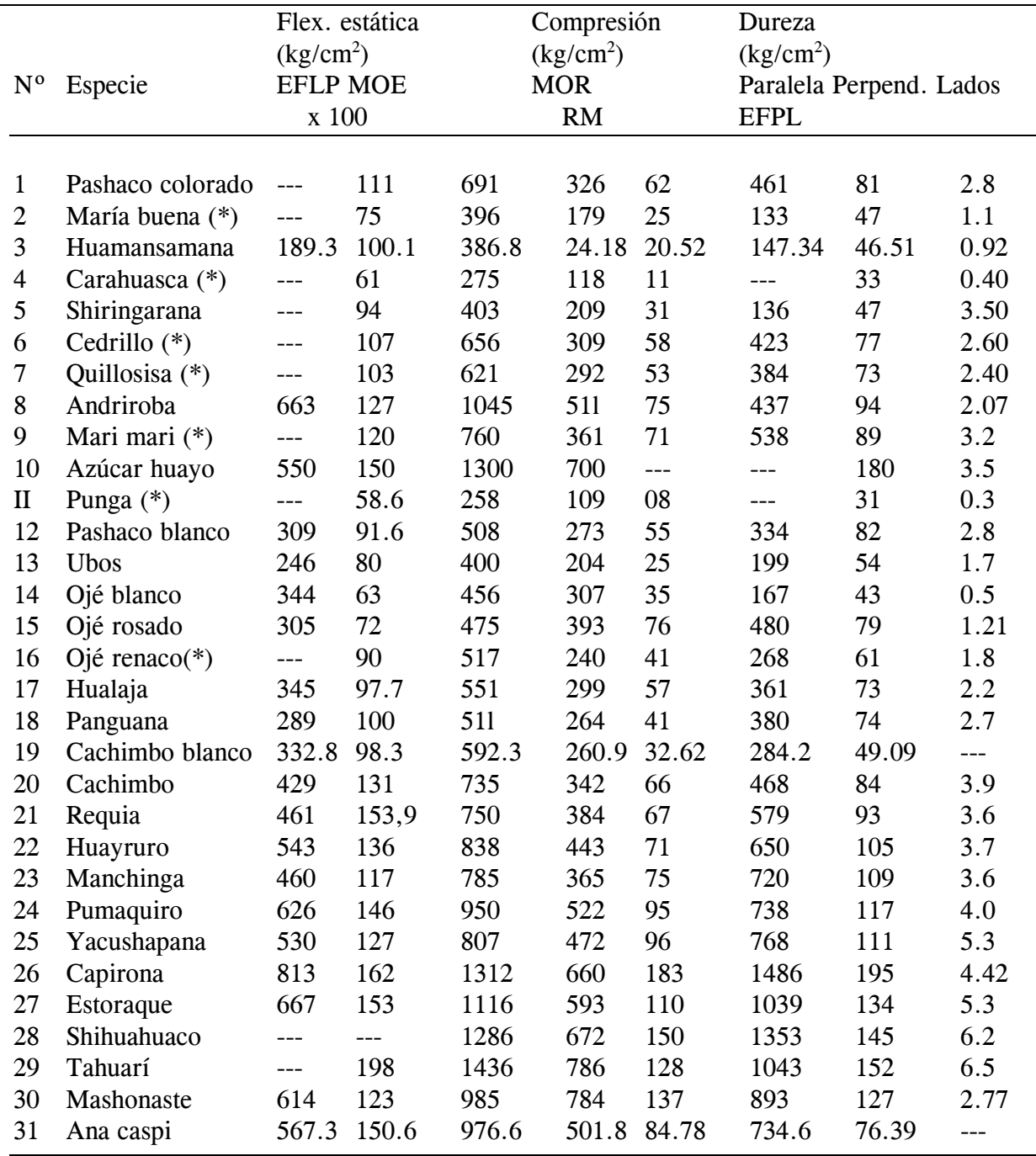

$\left.{ }^{*}\right) \quad=$ Valores estimados según procedimientos utilizado por Valderrama

EFLP = Esfuerzo de las fibras al límite proporcional

MOE = Módulo de elasticidad

MOR = Módulo de ruptura

$\mathrm{RM}=$ Resistencia máxima 


\begin{tabular}{|c|c|c|c|}
\hline \multirow{3}{*}{$\mathrm{N}^{\mathrm{o}}$} & \multicolumn{3}{|c|}{$\begin{array}{c}\text { Cuadro } 6 \\
\text { COMPORTAMIENTO TECNOLÓGICO }\end{array}$} \\
\hline & Especie & \multicolumn{2}{|l|}{ Aserrío } \\
\hline & & Comportamiento & Calificación \\
\hline 1 & Pashaco colorado & $\begin{array}{l}\text { Aserrarla inmediatamente, tensiones } \\
\text { internas, sierras con traba ancha. }\end{array}$ & Regular \\
\hline 2 & María buena & Aserrarlas inmediatamente & Bueno \\
\hline 3 & Huamansamana & Aserrarlas inmediatamente & Bueno \\
\hline 4 & Carahuasca & Aserrarlas inmediatamente & Bueno \\
\hline 5 & Shiringarana & Aserrarlas inmediatamente & Bueno \\
\hline 6 & Cedrillo & $\begin{array}{l}\text { Aserrarlas inmediatamente } \\
\text { Utilizar sierras bien afiladas, traba } \\
\text { intermedia en cuanto al ancho }\end{array}$ & Bueno \\
\hline 7 & Quillosisa & $\begin{array}{l}\text { Utilizar sierras bien afiladas, traba } \\
\text { intermedia en cuanto al ancho }\end{array}$ & Bueno \\
\hline 8 & Andiroba & Madera de buena calidad & Bueno \\
\hline 9 & Mari mari & $\begin{array}{l}\text { Madera de buena calidad, aserrarla } \\
\text { inmediatamente }\end{array}$ & Bueno \\
\hline 10 & Azúcar huayo & Madera muy dura, utilizar sierras estilitadas & Malo \\
\hline 11 & Punga & Madera muy suave, aserrarla inmediatamente & Bueno \\
\hline 12 & Pashaco blanco & Aserrarlas inmediatamente & Bueno \\
\hline 13 & Ubos & $\begin{array}{l}\text { Aserrarlas inmediatamente, madera muy } \\
\text { traposa }\end{array}$ & Bueno \\
\hline 14 & Ojé blanco & $\begin{array}{l}\text { Aserrarlas inmediatamente, madera muy } \\
\text { traposa }\end{array}$ & Bueno \\
\hline 15 & Ojé rosado & Aserrarlas inmediatamente & Bueno \\
\hline 16 & Ojé renaco & $\begin{array}{l}\text { Aserrarlas inmediatamente, desafila rápido } \\
\text { las sierras }\end{array}$ & Regular \\
\hline 17 & Hualaja & Aserrarlas inmediatamente & Bueno \\
\hline 18 & Panguana & Aserrarlas inmediatamente & Bueno \\
\hline 19 & Cachimbo blanco & Aserrarlas inmediatamente & Regular \\
\hline 20 & Cachimbo & ---- & ---- \\
\hline 21 & Requia & --- & Regular \\
\hline 22 & Huayruro & Trozas de diámetro muy grande & Bueno \\
\hline 23 & Manchinga & $\begin{array}{l}\text { Tensiones internas, dar orientación } \\
\text { radial a las tablas }\end{array}$ & Malo \\
\hline 24 & Pumaquiro & La madera despide astillas & Bueno \\
\hline 25 & Yacushapana & Madera muy dura, utilizar sierras estilitadas & Malo \\
\hline 26 & Capirona & $\begin{array}{l}\text { Tratamiento térmico, presencia rajaduras, } \\
\text { dar orientación radial a las tablas }\end{array}$ & Regular \\
\hline 27 & Estoraque & Trozas con diámetro muy pequeño & Regular \\
\hline 28 & Shihuahuaco & Madera muy dura, utilizar sierras estilitadas & Malo \\
\hline 29 & Tahuarí & $\begin{array}{l}\text { Trozas con diámetro pequeño, utilizar sierras } \\
\text { Estilitadas }\end{array}$ & Malo \\
\hline 30 & Mashonaste & $\begin{array}{l}\text { Madera abrasiva, presencia de sílice, tratamiento } \\
\text { térmico utilizar sierras estilitadas }\end{array}$ & Malo \\
\hline 31 & Ana caspi & $\begin{array}{l}\text { Madera abrasiva, presencia de sílice, utilizar } \\
\text { sierras estilitadas }\end{array}$ & Malo \\
\hline
\end{tabular}




\section{Cuadro 7}

COMPORTAMIENTO TECNOLÓGICO

\begin{tabular}{|c|c|c|c|}
\hline \multirow[t]{2}{*}{$\mathrm{N}^{\mathrm{o}}$} & \multirow[t]{2}{*}{ Especie } & \multicolumn{2}{|l|}{ Aserrío } \\
\hline & & Comportamiento & Calificación \\
\hline 1 & Pashaco colorado & Contracción baja, estable, alabeos y grietas & Malo \\
\hline 2 & María buena & $\begin{array}{l}\text { Contracción baja, moderadamente estable, } \\
\text { secado al aire }\end{array}$ & Regular \\
\hline 3 & Huamansamana & Contracción muy alta, estable & Bueno \\
\hline 4 & Carahuasca & Contracción media, estable, secado al aire & Bueno \\
\hline 5 & Shiringarana & $\begin{array}{l}\text { Contracción media, mediano, estable, secado } \\
\text { al aire }\end{array}$ & Regular \\
\hline 6 & Cedrillo & Contracción muy alta, estable, secado al aire & Regular \\
\hline 7 & Quillosisa & Contracción media, medianamente estable & Malo \\
\hline 8 & Andiroba & $\begin{array}{l}\text { Contracción media, estable, secado al aire, } \\
\text { leves grietas y rajaduras }\end{array}$ & Bueno \\
\hline 9 & Mari mari & Contracción media, estable, secado al aire & Bueno \\
\hline 10 & Azúcar huayo & Contracción media, estable & Malo \\
\hline 11 & Punga & Contracción media, inestable & Malo \\
\hline 12 & Pashaco blanco & $\begin{array}{l}\text { Contracción media, estable, alabeos y } \\
\text { rajaduras leves }\end{array}$ & Regular \\
\hline 13 & Ubos & $\begin{array}{l}\text { Contracción baja, medianamente estable, } \\
\text { alabeos leves }\end{array}$ & Regular \\
\hline 14 & Ojé blanco & $\begin{array}{l}\text { Contracción baja, inestable, secado artificial } \\
\text { programa de } 10 \text { días }\end{array}$ & Regular \\
\hline 15 & Ojé rosado & $\begin{array}{l}\text { Contracción regular, medianamente inestable } \\
\text { secado artificial programa de } 10 \text { días }\end{array}$ & Regular \\
\hline 16 & Ojé renaco & $\begin{array}{l}\text { Contracción baja, inestable, secado artificial } \\
\text { programa de } 10 \text { días }\end{array}$ & Regular \\
\hline 17 & Hualaja & Contracción media, estable & Bueno \\
\hline 18 & Panguana & $\begin{array}{l}\text { Contracción baja, estable, secado artificial Bueno } \\
\text { programa de } 10 \text { días }\end{array}$ & \\
\hline 19 & Cachimbo blanco & $\begin{array}{l}\text { Contracción baja, estable, secado artificial Bueno } \\
\text { programas de } 10 \text { días }\end{array}$ & \\
\hline 20 & Cachimbo & Contracción media, estable & Bueno \\
\hline 21 & Requia & Contracción alta, estable & Bueno \\
\hline 22 & Huayruro & Contracción baja, estable, secado artificial & Bueno \\
\hline 23 & Manchinga & Contracción media, estable, riesgo de alabeo & Bueno a reg. \\
\hline 24 & Pumaquiro & Contracción media, estable & Bueno \\
\hline 25 & Yacushapana & Contracción media, estable & Bueno \\
\hline 26 & Capirona & Contracción muy alta, estable, riesgo de alabeo & Regular \\
\hline 27 & Estoraque & Contracción media, estable & Bueno \\
\hline 28 & Shihuahuaco & Contracción media, estable & Bueno \\
\hline 29 & Tahuarí & Contracción media, estable & Bueno a reg. \\
\hline 30 & Mashonaste & Contracción baja, medianamente estable & Regular \\
\hline 31 & Ana caspi & Contracción media, estable & Regular \\
\hline
\end{tabular}


Cuadro 8

COMPORTAMIENTO TECNOLÓGICO

$\mathrm{N}^{\mathrm{o}} \quad$ Especie

1 Pashaco colorado

2 María buena

3 Huamansamana

4 Carahuasca

5 Shiringarana

6 Cedrillo

$7 \quad$ Quillosisa

8 Andiroba

9 Mari mari

10 Azúcar huayo

11 Punga

12 Pashaco blanco

13 Ubos

14 Ojé blanco

15 Ojé rosado

16 Ojé renaco

17 Hualaja

18 Panguana

19 Cachimbo blanco

20 Cachimbo

21 Requia

22 Huayruro

23 Manchinga

24 Pumaquiro

25 Yacushapana

26 Capirona

27 Estoraque

28 Shihuahuaco

29 Tahuarí

30 Mashonaste

31 Ana caspi
Durabilidad

Tto. preservador

Presencia de hongos, cromógenos y xilófagos Requiere ( en verde)

Susceptibles a ataques de hongos e insectos Requiere

Moderadamente resistente en seco

Requiere

Moderadamente resistente en seco

Requiere

Susceptibles a ataques de hongos e insectos Requiere

Capas superficiales atacadas por insectos

Requiere

(verde)

(verde)

Moderadamente resistente al ataque de hongos Requiere

(verde)

Resistente

No

En verde atacado por insectos (albura)

Requiere

(albura)

Resistente

No

Susceptible a ataque de agentes biológicos

Requiere

Susceptible a ataque de agentes biológicos

Muy susceptible al ataque de hongos e insectos

Susceptible al ataque de hongos e insectos

Requiere

Requiere

Susceptible a ataque de agentes biológicos

Susceptible a ataque de agentes biológicos

Requiere

Requiere

Requiere

Susceptible a ataque de agentes biológicos

Requiere

Moderadamente susceptible al ataque biológico Requiere

Moderadamente susceptible al ataque biológico Requiere

Moderadamente resistente

Resistente

Requiere

Moderadamente resistente al ataque biológico

No

Fácilmente atacados por agentes biológicos

Requiere

Resistente

Requiere

Resistente

No

Moderadamente resistente

No

Resistente

No

Resistente

No

Resistente

No

Resistente

No

Resistente
No

No 
Cuadro 9

COMPORTAMIENTO TECNOLÓGICO

\begin{tabular}{|c|c|c|c|c|c|c|c|c|c|c|c|c|}
\hline & \multirow[b]{2}{*}{ ESPECIE } & \multicolumn{4}{|c|}{ TRABAJABILIDAD } & \multicolumn{3}{|c|}{ RESISTENCIA } & \multicolumn{2}{|c|}{ MECANICA } & \multirow[b]{2}{*}{$\begin{array}{l}\text { Tena- } \\
\text { cidad }\end{array}$} & \multirow[b]{2}{*}{$\begin{array}{l}\text { Compor- } \\
\text { tauniento }\end{array}$} \\
\hline & & $\begin{array}{l}\text { Densidad } \\
\text { Básica } \\
\end{array}$ & $\begin{array}{l}\text { Grano } \\
\text { Contenido } \\
\end{array}$ & Dureza & Textura & $\begin{array}{l}\text { Compor- } \\
\text { tamiento }\end{array}$ & $\begin{array}{l}\text { Flexión } \\
(\mathrm{MOR}) \\
\end{array}$ & $\begin{array}{l}\mathrm{C} / 1 \\
\text { (R.M) }\end{array}$ & $\begin{array}{l}C \perp \\
\text { (EFLP) }\end{array}$ & $\begin{array}{l}\text { Cizalla- } \\
\text { miento }\end{array}$ & & \\
\hline $\begin{array}{l}1 \\
2 \\
3 \\
4 \\
5 \\
6 \\
7 \\
8 \\
9 \\
10 \\
11 \\
12 \\
13 \\
14 \\
15 \\
16 \\
17 \\
18 \\
19 \\
20 \\
21 \\
32 \\
23 \\
24 \\
25 \\
26 \\
27 \\
28 \\
29 \\
30 \\
31 \\
\end{array}$ & $\begin{array}{l}\text { Pashaco colorado } \\
\text { María buena } \\
\text { Huamansamana } \\
\text { Carahuasca } \\
\text { Shiringarana } \\
\text { Cedrillo } \\
\text { Quillosisa } \\
\text { Andiroba } \\
\text { Mari mari } \\
\text { Arucar huayo } \\
\text { Punga } \\
\text { Pashaco blanco } \\
\text { Ubos } \\
\text { Ojé blanco } \\
\text { Ojé rosudo } \\
\text { Ojé renaco } \\
\text { Hualaja } \\
\text { Panguana } \\
\text { Cachimbo blanco } \\
\text { Cachimbo } \\
\text { Requia } \\
\text { Huayruro } \\
\text { Vanchinga } \\
\text { Pumaquiro } \\
\text { Yacushapana } \\
\text { Capirona } \\
\text { Eqtoraque } \\
\text { Shihuahuaco } \\
\text { Tahuari } \\
\text { Mashonaste } \\
\text { Ana caspi } \\
\end{array}$ & $\begin{array}{l}\text { Media } \\
\text { Baja } \\
\text { Baja } \\
\text { M. baja } \\
\text { Baja } \\
\text { Media } \\
\text { Media } \\
\text { Media } \\
\text { Media } \\
\text { Alta } \\
\text { M. baja } \\
\text { Media } \\
\text { Baja } \\
\text { Baja } \\
\text { Media } \\
\text { Media } \\
\text { Media } \\
\text { Media } \\
\text { Media } \\
\text { Media } \\
\text { Media } \\
\text { Alta } \\
\text { Alta } \\
\text { Alta } \\
\text { Alta } \\
\text { M. alta } \\
\text { M. alta } \\
\text { M. alta } \\
\text { M. alta } \\
\text { M. alta } \\
\text { Alta } \\
\end{array}$ & 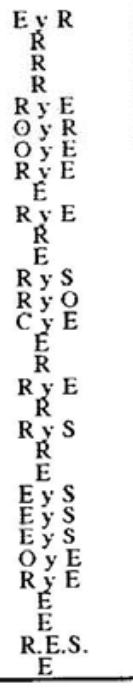 & $\begin{array}{l}\text { Media } \\
\text { Baja } \\
\text { Baja } \\
\text { Baja } \\
\text { Media } \\
\text { Media } \\
\text { Media } \\
\text { Media } \\
\text {-.. } \\
\text { Media } \\
\text { Baja } \\
\text { Baja } \\
\text { Media } \\
\text { Baja } \\
\text { Media } \\
\text { Media } \\
\text { Baja } \\
\text { Media } \\
\text { Media } \\
\text { Alta } \\
\text { Alta } \\
\text { Alta } \\
\text { Alta } \\
\text { M. alta } \\
\text { M. alta } \\
\text { M. altta } \\
\text { M. alta } \\
\text { Alta } \\
\text { Alta } \\
\end{array}$ & 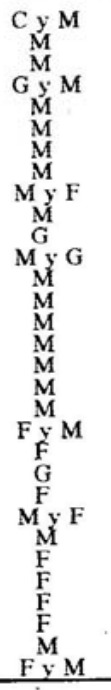 & $\begin{array}{l}\text { Regular } \\
\text { Bueno } \\
\text { Bueno } \\
\text { Regular } \\
\text { Regular } \\
\text { Bueno } \\
\text { Regular } \\
\text { Bueno } \\
\text { Regular } \\
\text { Regular } \\
\text { Malo } \\
\text { Regular } \\
\text { Regular } \\
\text { Regular } \\
\text { Regular } \\
\text { Regular } \\
\text { Buena } \\
\text { Regular } \\
\text { Bueno } \\
\text { Bueno(*) } \\
\text { Bueno } \\
\text { Malo } \\
\text { Regul( } \\
\text { Regul() } \\
\text { Regul(*) } \\
\text { Regul(*) } \\
\text { Regul(*) } \\
\text { Regul(*) } \\
\text { Regul(*) } \\
\text { Regul(*) } \\
\text { Regul(*) } \\
\end{array}$ & $\begin{array}{l}\text { Media } \\
\text { Baja } \\
\text { Baja } \\
\text { M. baja } \\
\text { Baja } \\
\text { Media } \\
\text { Media } \\
\text { M. alta } \\
\text { Media } \\
\text { M. alta } \\
\text { M. baja } \\
\text { Media } \\
\text { Baja } \\
\text { Baja } \\
\text { Baja } \\
\text { M. baja } \\
\text { M. baja } \\
\text { M. baja } \\
\text { M. baja } \\
\text { Baja } \\
\text { Baja } \\
\text { Baja } \\
\text { Baja } \\
\text { Media } \\
\text { Alta } \\
\text { M. alta } \\
\text { M. alta } \\
\text { M. alta } \\
\text { M. alta } \\
\text { Alta } \\
\text { Alta } \\
\end{array}$ & $\begin{array}{l}\text { Media } \\
\text { Baja } \\
\text { Media } \\
\text { M. baja } \\
\text { Baja } \\
\text { Media } \\
\text { Media } \\
\text { M. alta } \\
\text { Alta } \\
\text { M. alta } \\
\text { M. baja } \\
\text { Media } \\
\text { Baja } \\
\text { Media } \\
\text { Alta } \\
\text { Baja } \\
\text { Media } \\
\text { Media } \\
\text { Media } \\
\text { Media } \\
\text { Alta } \\
\text { Alta } \\
\text { Baja } \\
\text { M. alta } \\
\text { Alta } \\
\text { M. alta } \\
\text { M. alta } \\
\text { M. alta } \\
\text { M. alta } \\
\text { M. alta } \\
\text { M. altta } \\
\end{array}$ & $\begin{array}{l}\text { Media } \\
\text { Baja } \\
\text { Baja } \\
\text { Baja } \\
\text { Baja } \\
\text { Media } \\
\text { Media } \\
\text { Alta } \\
\text { Alta } \\
\text { M. baja } \\
\text { Media } \\
\text { Baja } \\
\text { Media } \\
\text { Alta } \\
\text { Media } \\
\text { Media } \\
\text { Media } \\
\text { Media } \\
\text { Media } \\
\text { Media } \\
\text { Alta } \\
\text { Alta } \\
\text { Alta } \\
\text { Alta } \\
\text { M. alta } \\
\text { M. alta } \\
\text { M. alta } \\
\text { M. alta } \\
\text { M. alta } \\
\text { Alta } \\
\end{array}$ & $\begin{array}{l}\text { Media } \\
\text { Baja } \\
\text { Baja } \\
\text { Baja } \\
\text { Baja } \\
\text { Media } \\
\text { Media } \\
\text { Alta } \\
\text { Media } \\
\text { M. alta } \\
\text { Baja } \\
\text { Media } \\
\text { Baja } \\
\text { Baja } \\
\text { Media } \\
\text { Media } \\
\text { Media } \\
\text { Media } \\
\text { Media } \\
\text { Media } \\
\text { Alta } \\
\text { Alta } \\
\text { Alta } \\
\text { Alta } \\
\text { Aita } \\
\text { M. alta } \\
\text { M. alta } \\
\text { M. aita } \\
\text { M. alta } \\
\text { M. alta } \\
\text { Media } \\
\end{array}$ & $\begin{array}{l}\text { Media } \\
\text { Baja Baja } \\
\text { M. baja } \\
\text { M. baja } \\
\text { Alta } \\
\text { Media } \\
\text { Media } \\
\text { Media } \\
\text { Alta } \\
\text { Alta } \\
\text { M. baja } \\
\text { Media } \\
\text { Baja } \\
\text { M. baja } \\
\text { Baja } \\
\text { Baja } \\
\text { Media } \\
\text { Media } \\
\text { Alta } \\
\text { Alta } \\
\text { Alta } \\
\text { Alta } \\
\text { Alta } \\
\text { M. alta } \\
\text { M. alta } \\
\text { M. alta } \\
\text { M. alta } \\
\text { M. alta } \\
\text { M. alta } \\
\text {--. }\end{array}$ & $\begin{array}{l}\text { Media } \\
\text { Baja } \\
\text { Baja } \\
\text { Baja } \\
\text { Media } \\
\text { Media } \\
\text { Alta } \\
\text { Alta } \\
\text { M. alta } \\
\text { M. baja } \\
\text { Media } \\
\text { Baja } \\
\text { Baja } \\
\text { Media } \\
\text { Baja } \\
\text { Media } \\
\text { Media } \\
\text { Media } \\
\text { Media } \\
\text { Alta } \\
\text { Alta } \\
\text { Alta } \\
\text { Alta } \\
\text { Alta } \\
\text { M.alta } \\
\text { M.alta } \\
\text { M.alta } \\
\text { M.alta } \\
\text { M.alta } \\
\text { Alta } \\
\end{array}$ \\
\hline
\end{tabular}




\section{Cuadro 10}

\section{RELACIÓN : DENSIDAD BÁSICA Y COMPORTAMIENTO TECNOLOGICO DE LA MADERA}

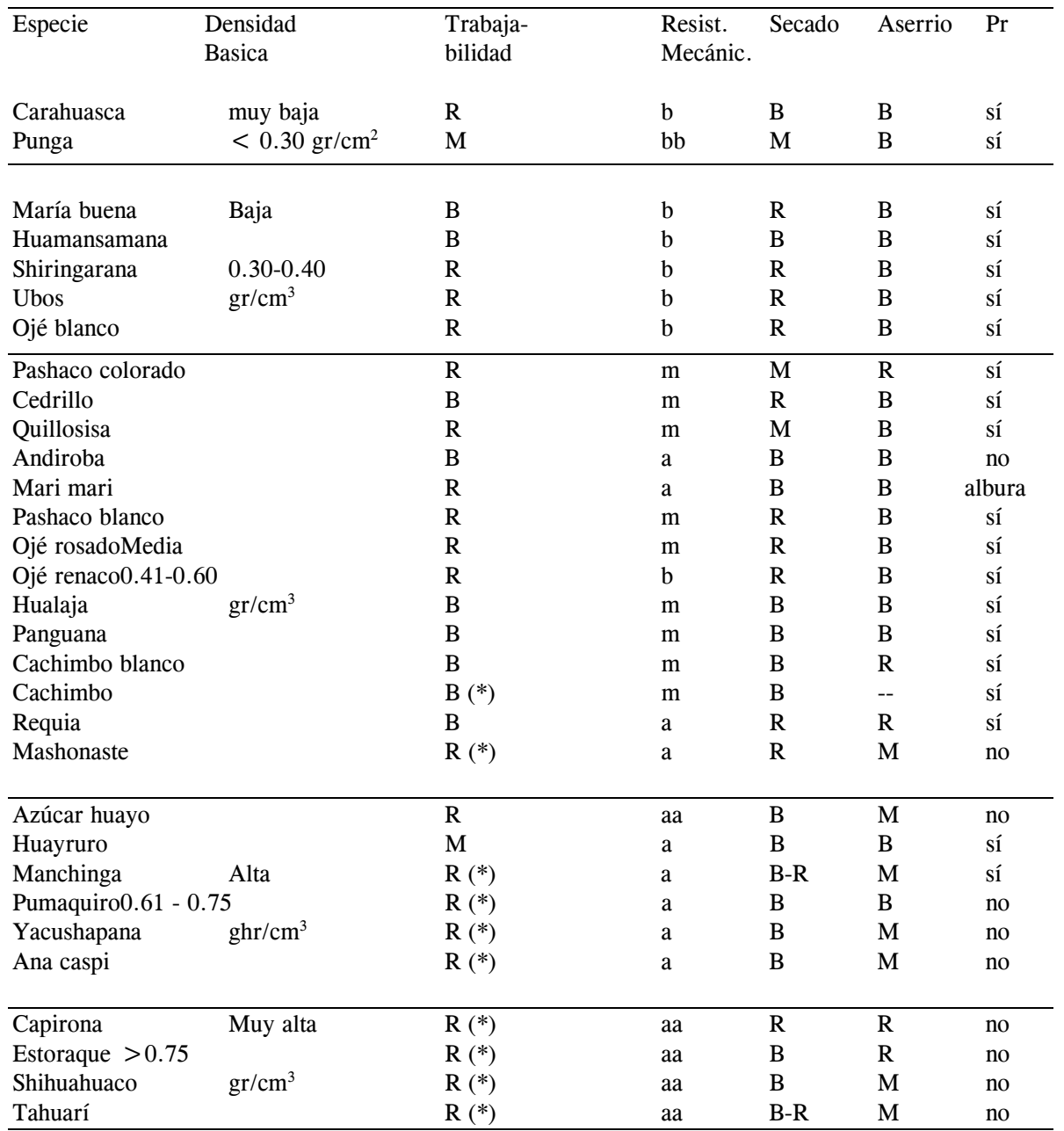

\begin{tabular}{ll}
\hline $\mathrm{M}=$ Malo & $\mathrm{bb}=$ Muy baja \\
$\mathrm{R}=$ Regular & $\mathrm{b}=$ Baja \\
$\mathrm{B}=$ Bueno & $\mathrm{m}=$ Media \\
$\mathrm{a}=$ Alta & $\mathrm{a}=$ Muy alta
\end{tabular}

$(*)=$ Problemas de desafilado de sierras y cuchillos 


\section{Cuadro 11}

USOS PROBABLES DE LA MADERA POR ESPECIES

\begin{tabular}{|c|c|c|c|c|c|c|c|c|c|c|c|c|c|c|c|c|}
\hline \multirow[b]{2}{*}{$N^{\circ}$ ESPECIES } & \multicolumn{3}{|c|}{$\begin{array}{l}\text { CONSTRUCCTON } \\
\text { DE VIVTENDAS } \\
\end{array}$} & \multirow{2}{*}{$\begin{array}{l}\text { E } \\
\text { a } \\
\text { s } \\
: \\
\text { f } \\
r \\
\text { a } \\
\text { d }\end{array}$} & \multirow{2}{*}{ 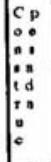 } & \multirow{2}{*}{$\mid \begin{array}{ll}M & r \\
u & i \\
0 & a \\
n \\
1 \\
0\end{array}$} & \multirow{2}{*}{$\mid \begin{array}{ll}E & r \\
b & i \\
: & a \\
n \\
i \\
\vdots \\
i \\
0\end{array}$} & \multirow{2}{*}{$\begin{array}{l}\mathrm{L} \\
\mathrm{a} \\
\mathrm{m} \\
\mathrm{i} \\
\mathrm{n} \\
\mathrm{a} \\
\mathrm{d} \\
0\end{array}$} & \multirow{2}{*}{ 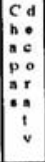 } & \multirow{2}{*}{\begin{tabular}{c}
$M$ \\
$\because \because$ \\
$\mathrm{n} r$ \\
$\mathrm{~g} \mathrm{r}$ \\
$0 \mathrm{a}$ \\
$\mathrm{m}$ \\
$\mathrm{d}$ \\
\hdashline \\
\hdashline
\end{tabular}} & \multirow{2}{*}{$\begin{array}{l}\mathrm{Cr} \\
\mathrm{a} i \\
\mathrm{ra} \\
\mathrm{r} \\
\mathrm{o} \\
\mathrm{c} \\
0\end{array}$} & \multirow{2}{*}{$\mid \begin{array}{ll}D & 1 \\
u & 0 \\
r i \\
m \\
i \\
0 \\
n\end{array}$} & \multirow{2}{*}{$\mid \begin{array}{ll}c & a \\
a & i \\
j & i \\
0 & i \\
n & i \\
0 & i \\
r & a \\
i & n\end{array}$} & \multirow{2}{*}{ 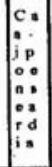 } & \multirow{2}{*}{$\begin{array}{l}A \\
: \\
\vdots \\
\vdots \\
\vdots \\
\vdots\end{array}$} & \multirow{2}{*}{$\begin{array}{l}P p \\
u p \\
1 p \\
p \\
0 \\
0 \\
y\end{array}$} \\
\hline & 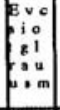 & $\begin{array}{l}\mathrm{c} d \\
\mathrm{a} 0 \\
\mathrm{r} \\
\mathrm{po} \\
\mathrm{ib}\end{array}$ & $\begin{array}{l}P p \\
i a \\
\text { ir } \\
o q \\
\text { of }\end{array}$ & & & & & & & & & & & & & \\
\hline 01 PASHACO COLORADO & & $x(1)$ & & $x$ & & $x(1)$ & & & & & & & $x$ & $x$ & & $\mathrm{x}$ \\
\hline 02 MARIA BUENA & & $x(1)$ & & & & $x(1)$ & & & & & & & $x$ & $x$ & & $\mathrm{x}$ \\
\hline 03 HUAMANSAMANA & & $x(1)$ & & & & $x(1)$ & & & & & & & $x$ & & & $x$ \\
\hline O4 CARAHUASCA & & $x(1)$ & & $\mathrm{x}$ & & $x(1)$ & & & & & & & $x$ & $x$ & & $\mathrm{x}$ \\
\hline OS SHIRINGARANA & & $x(1)$ & & & & & & & & & & & $x$ & $x$ & & $\mathrm{x}$ \\
\hline 06 CEDRILLO & $x(2)$ & $x$ & & & & $\mathrm{x}$ & $\mathrm{x}$ & & & & & & & $x$ & & \\
\hline 07 QUILLOSSA & $x(2)$ & $x$ & & $x$ & & & & & & & & & & $x$ & & \\
\hline OB ANDIROBA & $x$ & $\mathrm{x}$ & & & & $x$ & $x$ & & $\mathrm{x}$ & & $\mathrm{x}$ & & & & & \\
\hline O9 MARI MARI & $x$ & $\mathrm{x}$ & $\mathrm{x}$ & & $x$ & & & & & $\mathrm{x}$ & $\mathrm{x}$ & & & & & \\
\hline 10 AZUCAR HUAYO & $x$ & $\mathrm{x}$ & $\mathrm{x}$ & & $x$ & & & & $x$ & $\mathrm{x}$ & & $\mathrm{x}$ & & & $x$ & \\
\hline 11 PUNGA & & & & & & & & $x(2$ & & & & & $x$ & & & $x$ \\
\hline 12 PASHACO BLANCO & & $x(1)$ & & $x$ & & & & & & & & & $x$ & $x$ & & \\
\hline 13 UBOS & & $x(1)$ & & $\mathrm{x}$ & & $x$ & & & & & & & $x$ & $x$ & & \\
\hline 14 OIE BLANCO & & $x(1)$ & & $x$ & & $x$ & & & & & & & $x$ & $x$ & . & \\
\hline 15 OIE ROSADO & $x(2)$ & $x(1)$ & & $x$ & & $x$ & $x$ & & $\mathrm{x}$ & & & & & & & \\
\hline 16 OIE RENACO & & $x(1)$ & & $\mathrm{x}$ & & $\mathrm{x}$ & & & $x$ & & & & & & & \\
\hline 17 HUAJALA & $x(2)$ & $x(1)$ & & & & $x$ & $\mathrm{x}$ & & & & & & $x$ & $x$ & & $\mathrm{x}$ \\
\hline 18 PANGUANA & (2) & $x(1)$ & & & & $\mathrm{x}$ & $\mathrm{x}$ & $\mathrm{x}$ & & & & & $x$ & $x$ & & \\
\hline 19 CACHIMBO BLANCO & $x$ & $\mathbf{x}$ & $\mathrm{x}$ & & & $\mathrm{x}$ & $x$ & & & $x$ & & & & & $\mathrm{x}$ & \\
\hline 20 САCHIMBO & $x$ & $x$ & $\mathrm{x}$ & & & $\mathrm{x}$ & $x$ & & & $\mathrm{x}$ & & & & & $x$ & \\
\hline 21 REQUIA & $x$ & $x$ & $\mathrm{x}$ & & & $\mathrm{x}$ & $x$ & & $\mathrm{x}$ & $x$ & $\mathrm{x}$ & & & & & \\
\hline 22 HUAYRURO & $x$ & $x$ & $\mathrm{x}$ & & $x$ & $\mathrm{x}$ & $x$ & & & & $x$ & $\mathrm{x}$ & & $x$ & & \\
\hline 23 MANCHINOA & $\mathrm{x}$ & $x$ & $\mathrm{x}$ & & & $x$ & & & & $\mathrm{x}$ & & $x$ & & $x$ & $\mathrm{x}$ & \\
\hline 24 PUMAQLTRO & $x$ & $\mathrm{x}$ & $x$ & & $x$ & $x$ & $x$ & & $\mathrm{x}$ & $x$ & & & & & & \\
\hline 25 YACUSHAAPANA & $x$ & $x$ & $\mathrm{x}$ & & & $x$ & $x$ & & $\mathrm{x}$ & $\mathrm{x}$ & & $x$ & & & $x$ & \\
\hline 26 CAPIRONA & $x$ & $x$ & $x$ & & & & & & & $x$ & & & & & & \\
\hline 27 ESTORAQUE & $\mathrm{x}$ & & $x$ & & $x$ & & & & & $x$ & & $x$ & & & & \\
\hline $2 B$ SHIHUAHUACO & $x$ & $x$ & $x$ & & $x$ & & & & & $x$ & & $x$ & & & & \\
\hline 29 TAHUARI & $x$ & & $x$ & & $x$ & & & & & $\mathrm{x}$ & & $x$ & & & $\mathbf{x}$ & \\
\hline 30 MASHONASTE & $x$ & $x$ & $\mathrm{x}$ & & $x$ & & & & & & $x$ & $x$ & & & & \\
\hline 31 ANA CASPI & $x$ & & $x$ & & $x$ & & & & & & $x$ & $x$ & & & & \\
\hline
\end{tabular}

(1) = Su utilización se limita previo preservado a piesa vortas. cajoncría de mucbles interiores

- de viviendas, , iclo razoo; etc.

(2) = Con ciertas limitaciones. 